\title{
Temporal context effects with two judgmental languages
}

WILLIAM G. BRAUD ANO STEPHEN W. HOLBORN ${ }^{1}$

UNIVERSITY OF IOWA

One hundred forty-four Ss judged the durations of 5-sec. test tones after pre-exposure to either long (30 sec.), short $(0.5 \mathrm{sec}$ ), or no pretraining tones. Half of the Ss made duration judgments in terms of a "situationally relative, novel, arbitrary, and restricted" 7-point rating scale; half of the $S S$ estimated durations directly in seconds-a well-practiced, "absolute, extensive, and extra-experimentally anchored" judgmental language. Direct estimation in seconds did not show temporal contrast effects, while judgments in terms of the rating scale did show such effects. It was suggested that these effects were not perceptual, but were contributed by a semantic or linguistic process operative in the rating situation but not in the direct estimation task.

It has been suggested (Campbell, Lewis, \& Hunt, 1958; Krantz \& Campbell, 1961) that in the judgmental phenomena of contrast or adaptation level effects observed in studies employing human Ss two processes are operative: perceptual or end-organ effects and semantic or linguistic effects. The former categories include distortions in identity judgments, illusions, or shifts in the appearance of stimuli independent of the particular language used in judgments. The latter categories include effects dependent upon the specific "situationally relative, novel, arbitrary, and restricted" judgmental language defined by the E. In any given situation the particular contribution of each effect would depend upon the specific task employed. Campbell, Lewis, \& Hunt (1958) attempted to assess the perceptual effect alone through the use of an "absolute, extensive, and extra-experimentally anchored" judgmental language not subject to the usual semantic effects. The usual contrast or adaptation level effects were observed. Krantz \& Campbell (1961) reported a study in which about one-half of the effects of context on ratings of length were attributed to the linguistic process, the other half to the perceptual process. In these studies both perceptual and linguistic effects, and perceptual effects alone were found. It should be possible to develop a situation in which only linguistic effects would be observed. In view of the finding of Campbell, Hunt, \& Lewis (1958) that a more detailed rating scale is more resistant to context effects than a less detailed one, and the finding that Ss who are familiar with judgmental categories are less influenced by a shift in context (Campbell, Lewis, \& Hunt, 1958), it would seem that as rating categories are made more and more "objective, absolute, and detailed," and as S's familiarity with these categories increases, the mag- nitude of perceptual contrast effects would decrease. Since the direct estimation of stimulus values in terms of "absolute" measurement categories (ounces, degrees, etc.) is the limiting case of a detailed scale, it would seem that in a situation involving only wellpracticed measurement categories, perceptual contrast effects would not be observed. Such a well-practiced measurement dimension is that used in time estimation. If the above reasoning is correct, direct estimation of durations in seconds should not show contrast effects, while judgments of durations in terms of a "situationally relative, arbitrary, restricted, and novel" rating scale should show such effects-these effects being contributed by the semantic or linguistic process operative in the rating situation but not in the direct estimation task.

\section{Method}

Series of $300-\mathrm{Hz}$ auditory tones generated by a Hewlett Packard Model 200D audio oscillator and timed by Grason-Stadler timers were pre-recorded and presented to Ss via a tape recorder. The Ss, 144 Introductory Psychology students, were run in six groups of 24 Ss each (12 male, 12 female). Groups SS and SR were pre-exposed to a series of twelve 0.5 -sec. tones; Groups LS and LR were pre-exposed to a series of 1230 -sec. tones; Groups NS and NR received no preexposure to tones. Intertone intervals were $10 \mathrm{sec}$.; total time spent in the pretraining situation was constant for all Ss. Following pretraining, all Ss were exposed to a series of 30 test tones: 10 tones each of 1 -sec., 5-sec., and 10-sec. duration. During this test phase, three $5-\mathrm{sec}$. tones were presented first, after which the remainder of the 30 tones was presented in random order; intertone intervals were again $10 \mathrm{sec}$. The Ss were instructed to judge each tone as it was presented, each $\mathrm{S}$ making a total of 42 judgments; thus, in terms of judgments, there was no sudden change from pretraining to testing. Groups SS, LS, and NS estimated tone durations directly in seconds; Groups SR, LR, and NR judged tone durations in terms of a 7-point rating scale with points "1," "4," and "7" labeled "very short," "average," and "very long," respectively. Results and Discussion

Figure 1 represents each group's mean judgment of each of the ten 5-sec. test stimuli in terms of the 7-point rating scale. The usual contrast or adaptation level effects obtained: durations of standard test tones were overestimated by Ss who had received prior experience with short tones and underestimated by those 


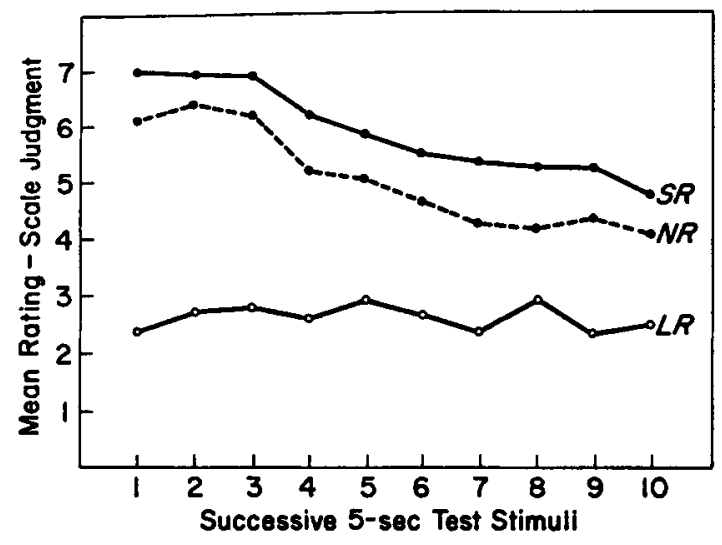

Fig. 1. Mean rating scale judgments as a function of successive test stimuli.

Ss who had previously experienced long tones. Differences among groups were significant ( $F=187.9$, $\mathrm{df}=2 / 69, \mathrm{p}<.001$ ).

There was no evidence of a contrast effect, however, in the direct estimation data. Figure 2 represents each group's mean estimates of the 10 test stimuli, expressed in seconds. Differences among groups were not reliable $(F=3.0, \mathrm{df}=2 / 69, \mathrm{p}>.05)$. Thus neither linguistic nor perceptual contrast processes were operative in this direct estimation task. In view of these latter data, it would appear that the contrast effects found in the rating scale situation were due solely to linguistic or semantic processes dependent upon the "situationally relative, novel, arbitrary, and restricted" 7-point rating scale.

In both the rating scale and direct estimation situations the within-Ss successive test stimuli effect was statistically significant $(F=131.6, d f=9 / 621, p<.001$ and $F=20.6, d f=9 / 621, p<.001$, respectively). The groups-by-successive presentations interaction effect was significant for ratings $(F=21.3$, df $=18 / 621, p<$ $.001)$, but not for direct estimations $(F=1.3, \mathrm{df}=18 / 621$,

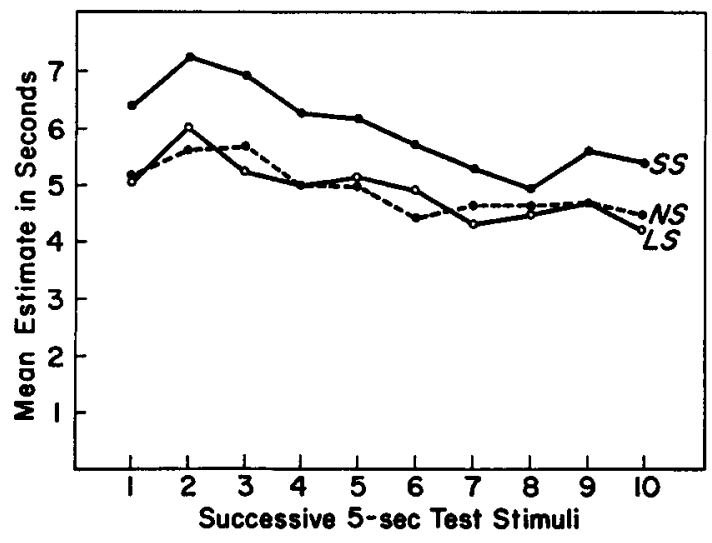

Fig. 2. Mean estimates in seconds as a function of successive test stimuli.

p>.05). Judgments of tone durations decreased with successive presentations of test tones for all groups except Group LR which judged the tones to be of the same duration throughout the test phase. Adaptation level theory would predict eventual convergence of the curves in the rating scale situation since exposure to identical stimulus sequences would yield a common adaptation level for all three groups. The data are not inconsistent with such convergence.

\section{References}

Campbell, D. T., Hunt, W. A., \& Lewis, N. A. The relative susceptibility of two rating scales to disturbances resulting from shifts in stimulus context. J. appl. Psychol., 1958, 42, 213-217.

Campbel1, D. T., Lewis, N. A., \& Hunt, W. A. Context effects with a judgmental language which is absolute, extensive, and extraexperimentaliy anchored. J. exp. Psychol., 1958, 55, 220-228.

Krantz, D. L., \& Campbell, D. T. Separating perceptual and linguistic effects of context shifts upon absolute judgment. $J$. exp. Psychol., 1961, 62, 35-42.

\section{Note}

1. The authors are indebted to Dr. H. P. Bechtoldt for stimulation of their research. 